\title{
Journal of the American Medical Association.
}

EDITED FOR THE ASSOCIATION BY N. S. DAVIS.

PUBLISHED WEEKLY.

Vol. IV.

Chicago, June I3, 1885 .

No. 24 .

\section{ORIGINAL ARTICLES.}

\section{SUCCESSFUL RESULTS OF A NEW TREATMENT FOR DIPHTHERIA. ${ }^{1}$}

\author{
BY R. J. NUNN, M.D. \\ OF SAVANNAH, GEORGIA.
}

In Gaillard's Medical Journal, January, I884, I published a paper on the "Use of Peroxide of $\mathrm{Hy}$ drogen in Diphtheria," which was intended only to bring before the Profession the value of that antiseptic as a local application in the disease. Although Peroxide of Hydrogen acts energetically and favorably when topically applied dissolving soft membrane and disinfecting the part, it seems to be absolutely devoid of constitutional action and has not the power to prevent the sequela of the disease in question, indeed a knowledge of its constituent elements would lead naturally to such a conclusion. This is painfully and certainly demonstrated in the following case :

Case I. The patient was a young lady of seventeen years of age, in whom there was a tendency to tonsillar and pharyngeal congestion. The attack of diphtheria was preceded by one of tonsillitis of a mild form. 'The first symptoms were nasal, and the first visible membrane was upon the left tonsil, which was entirely covered within twenty-four hours with a patch of membrane about three-quarters of an inch in diameter. At this time, the patient could not breathe through the nose. The application of the peroxide was now commenced in earnest, and the assault was made simultaneously from all quarters. The brush, spray, gargle and douche being all called into requisition, so that the parts may be said to have been constantly bathed with the remedy, but no other medium was used in the treatment of the case. Within a week, patches of membrane, some of which were not less than two square inches in area were detached from the vault of the pharynx. Every trace of deposit had disappeared, and the case was discharged, and in a day or two she returned to her home in the country. In ten days her family and her physician wrote that she was attacked with a partial paralysis, which soon became general and total with severe local pains, and in another week she died, just seventeen days after the disappearance of the diphtheritic deposit.

${ }^{1}$ Read in the Section of Practical Medicine, Materia Medica, and Physiology, at the Thirty-Sixth Annual Meeting of the American Medical Association.
From the history of this case, it became evident that a constitutional antiseptic of considerable power must be found, which would prevent the development of the diphtheritic poison and preserve the nerve centers from its destructive influence. It has been found that the most powerful antiseptic and germicide was biniodide of mercury, as will be seen from the following table of Dr. S. Miguel: It gives the weight in grammes of each of these microbicides capable of rendering imputrescible one litre of beef tea:

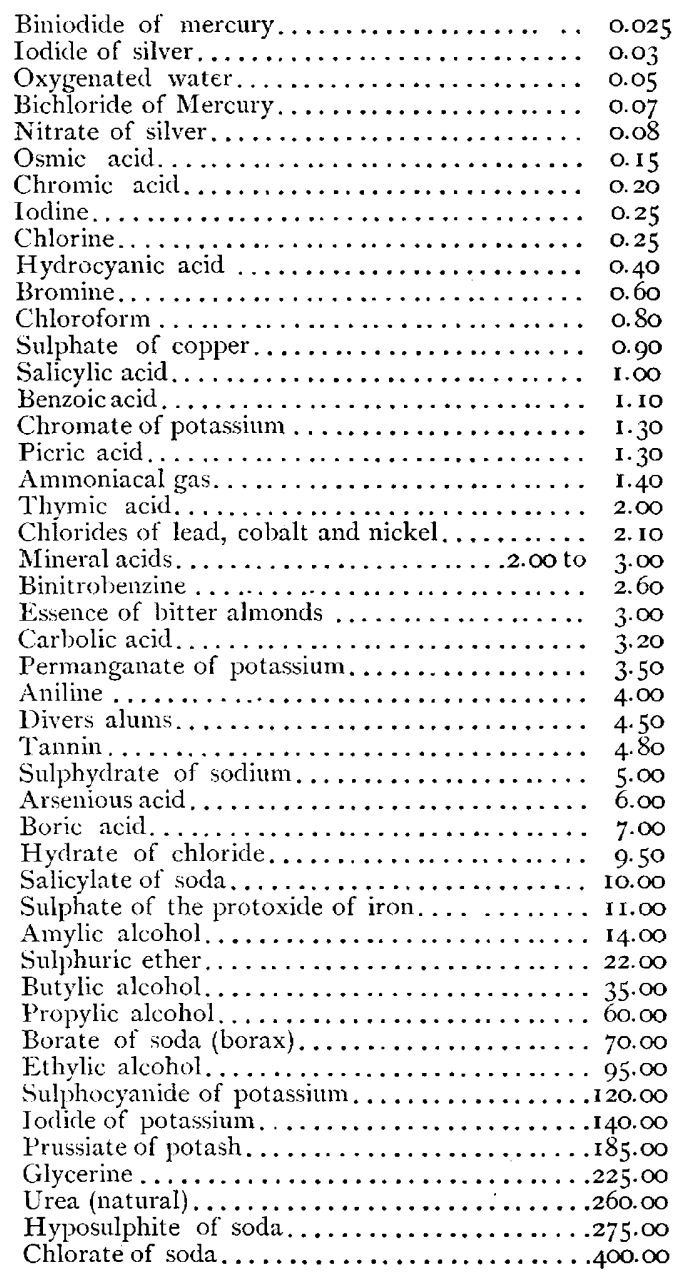

"Most of these substances act by paralyzing the evolution of the microbic germs, and by destroying the adult bacteria, but they have no effect on the 
germs of the bacteria. Certain substances, however, have by their chemical action the power of completely destroying the germs of the bacteria, and to this class Dr. Miguel has applied the term 'sporicides.' 'The principal among them, are the preparations of mercury, and the salts of silver, which in a solution of $1-10,000$ destroy the germs of microbes as surely as a dry temperature of $150^{\circ} \mathrm{C}$. $\left(302^{\circ}\right.$ in a few days F.) prolonged during several hours. Iodine, chlorine and bromine, and the mineral acids come next, but the microbicide par excellence is heat, which raised to $\mathrm{I}$ io $\mathrm{C}$. ( $130^{\circ} \mathrm{F}$.) for liquids, and to above $150^{\circ} \mathrm{C}$. $\left(302^{\prime} \mathrm{F}\right.$.) for solids, has been found sufficient to effectually destroy the germs of the microbes."

That a large quantity of a powerful germicide is not necessarily required to attain the object in view, is admirably proved by the following extract from a forgotten source:

"The cultivation of micro-organisms which is now every where carried on, enables, us to realize the smallness of the change, which in many cases, suffices to convert a highly nutritive liquid into one incapable of supporting microscopic life. Various important essays bearing upon this subject have been recently published in the Rerue Scintifique. M. Boulsy there draws attention to the results obtained by M. Raulin in the cultivation of the microscopic plant named Aspergillus niger. The omission of potash from Raulin's liquid, suffices to make the produce fall to one twenty-fifth of the amount collected when potash is present. 'The addition of an infinitesimal amount of a substance inimical to the life of a plant is attended with still more striking results. For example, one part in sixteen humdred-thousand of nitrate of silver added to the licuid entirely stops the growth of the plant. And now we come to the important application of this fact, which has been indicated by M. Duclaux. Supposing the aspergillus to be a human parasite, a living contagium, capable of self-multiplication in the human blood, and of so altering the constitution of that liquid as to produce death, then the introduction into the blood of a man weighing sixty kilogrammes of five milligrammes of the nitrate of silver would insure, if not the total effacement of this contagium, at all events the neutralization of its power to destroy life."

If then five milligrammes of nitrate of silver would produce this result, it was evident that a much less quantity of biniodide of mercury, which is three times as powerful, would probably answer the same purpose; but another important indication could be fulfilled at the same time-that of thoroughly disinfecting the mouth and fauces by means of a dilute solution of the "sporicide" kept constantly flowing over the mucous membrane. Following these indications, a weak solution of biniodide of mercury (one part to two thousand, one grain to about four ounces) in water was prepared, using iodide of potassium to insure the solution, and also diffusion of the remedy through the system. It was proposed to give of this five or six drops every ten or fifteen minutes, and it was intended that it should be used as a spray to the nostril if such a course became necessary. Experiences had shown that in cases having a thick de- posit, some agent was required which would act upon and soften the membrane, preparing it for the solvent power of the peroxide of hydrogen on the one hand, and permitting the more thorough action of the "sporicide" solution on the other. To fulfill this indication, and following a French suggestion, papayotin was selected as being a much more powerful digestive agent, although somewhat similar in its apparent action to pepsin, pancreatin, trypsin, etc., and possessing in addition the property no less singular than valuable of acting equally as well in fluids having an acid or an alkaline reaction. The salient points of the treatment adopted are here as foreshadowed :

First. The frequent application to the membrane of the peroxide of hydrogen which will dissolve such portions of it as are soft and flocculent. The spray, with or without the soft camel's hair brush, will be found most useful in using this remedy, which can be applied also to the nasal passages.

Secondly. Having thoroughly cleaned away all the membrane which can thus be got rid of, powdered papayotin is applied to that which semains by means of a powcier-blower, after which no food or medicine is given for twenty or thirty minutes, the object being to avoid as much as possible removing the papayotin from the membrane.

Thirdly After twenty minutes or half an hour, the use of the general germicidal solution, (the solution of the biniodide of mercury having thus far proved itself superior to any other), is resumed in the manner just indicated, that is to say, a few drops admin istered every ten or fifteen minutes.

This course is pursued until the membrane has. disappeared, when the use of the peroxide of hydrogen and of the papayotin is discontinued, but the sporicidal solution is still to be administered, but at more distant intervals, nor should its administration be stopped until all danger of paralysis is passed. 'The amount of medicine thus administered, is marvelously small when compared with the results obtained, a single grain sufficing for from three days to a week even in the height of the disease. 'The longest period for which the biniodide was used in any one case was two months, and towards the last of that time but three doses a day were given. Occasionally, when there is evident depravement of the blood, a little syrup of the iodide of iron, proportioned to the age of the patient, has been added to the biniodide solution. Finally, if there is evidence that the disease has de veloped in the home of the patient, I strongly recom mend removal to another house whenever it can be possibly effected.

Effect of iodide of potassium.-There seems to be some probability that iodide of potassium acts specifically, or at least assists in the specific action of the mercurial salt. Although this salt occupies a low position in the scale of germicides, it certainly can exist in the system in quantities quite sufficient to materially modify bacterial development therein. The urine passed by patients who were taking iodide of potassium, and which held the salt in solution as evidenced by chemical reaction has been kept by me for months without undergoing any apparent change, while the urine from the same patients before the ad- 
ministration of the medicine underwent rapid de- patient recovered from the direct attack, still the composition. A similar condition has been observed death resulted from the secondary effects of the disto exist during the administration of salicylic acid ease, and should therefore be credited to that malady. (Medical World, Vol. III. P. 4), which may in some A detailed account of this case has been already given. measure account for its value in the treatment of diphtheria.

If now the iodide of potassium, after being administered, can show itself in the urine in sufficient quantity to materially retard bacterial development, it certainly seems highly propable that its presence in the blood must tend to the production of a like result. It is therefore most unlikely that the iodide of potassium is an idle spectator of the germicidal operations of the biniodide of mercury, or simply a carrier of the latter salt, but it is rather present in the double rôle of a vehicle and a germicidal ally. In accordance with this view, the strength of the solution of iodide of potassium used to dissolve the biniodide of mercury should be as great as the comfort of the patient will permit. That the biniodide of mercury is present in the blood is proved by the fact that "during the internal use of the mercurial preparations the urine always contained mercury." (Neubauer and Vogel on the urine, P. I 38 ). For this reason the urine should be frequently examined, and the presence in it of the iodide of potassium be verified by analysis, thus insuring the permeation of the system by the germicidal salts.

The rapid diffusibility of the iodide of potassium is a great argument in favor of its employment. It is reported to have been detected in the urine six minutes after administration, and according to $M$. Melseus, the activity of the mercurial salts is greatly heightened by its use. Again, by the constant use of small doses of the iodohydroargyrate solution the elimination by the kidneys is balanced, and a constant stream of the germicide is, as it were, kept flowing through the system. Theoretically, the frequent doses of the medicine are demanded to prevent the germination of the bacterial elements of the disease, which may take place at short intervals of time, the exact period being at present unknown. Whether this theory be absolutely correct or not, the plan of administering the medicine, founded upon it works well in practice. Incidentally, I would mention that this remedy acts equally as well in follicular tonsilitis, and in aphthous deposit in various localities. It is worthy of trial wherever there is an abnormal process going on dependent upon bacterial growth.

Alkaline lodides.-The peculiar action of the iodide of potassium, naturally suggests the substitution for it of some other similar salt, such as the iodide of sodium or the iodide ammonium. Whether any of them would be an improvement upon the iodide of potassium, I am unable at present to say; it is to be hoped, however, that further observations will be made in this direction. The antiseptic powers of bromine would also suggest for its salts a trial.

Results - Up to the time of this writing, peroxide of hydrogen has been used by me, either alone or combined with other remedies. In fourteen cases of these, three terminated fatally, and eleven recovered without any sequela. Of the three fatal cases, one was treated with the peroxide alone, and, although the years of age, which had been ailing with cold in the head, accompanied by an acrid discharge for several weeks, with occasional epistaxis. The appearance of the child was markedly that of blood poisoning. There was low fever from temp. IoI, pulse roo, skin dry and sallow, upper lip excoriated from the nasal discharge, angle of the mouth cracked and scabbed, teeth covered with sordes, gums spongy and bleeding easily, tongue dry and black and with a tendency to crack; abdominal symptoms there were none, nor was any membrane visible in nostrils or in the throat. I treated the case for constitutional disturbance, but kept a constant watch for the membrane of diphtheria so as to apply local remedies. In two days a slight membraneous deposit was visible in the left nostril, and in another day, the tonsils were invaded. The treatment herein advanced was now adopted, except that a solution of corrosive sublimate, as recommended by Dr. Geo. G. Lyon, (Jolrnal American Medical AssociaTron, July 25, I 884, p. 94,) was used instead of that of the biniodide. This was done on the faith of various publications, and the report of personal acqaintances, who were using it in their practice. The treatment was faithfully pursued, but with the dying year my patient passed away, a victim to blood poisoning.

Case 3.-I was called in consultation to see a child about four years old, who had diphtheria about a week and was gradually getting worse under chlorate of potash, tincture of iron, quinine with a spray of lime water and carbolic acid. Peroxide of hydrogen was prescribed in spray, and pepsin blown in to the pharynx, our supply of papayotin being exhausted. After a week of anxiety and suffering, death came to the relief of our little patient.

These three are the only fatal cases which have occured in my practice, in which the peroxide of hydrogen has been employed. It will be observed that in none of these cases was the full treatment, with the biniodide of mercury carried out. In the remaining cases, eleven in all, in which the new treatment was employed in its entirety, the results were eminently satisfactory, there not being a fatal case to record. The following is quite a typical case:

Case 4.-. On November I 5, I was called to see $\mathrm{R}$. C., aged three years, with a marked diphtheritic deposit on both tonsils. The mother of the child said that for six weeks at least, there had been an acrid discharge from the nose with odema of the nasal mucous membrane and epistaxis. These symptoms were passed by unnoticed, until the appearance of the membrane in the throat. I prescribed peroxide of hydrogen by spray and brush to be used frequently. Next day the membrane could be seen extending downward from the roof upon the back of the pharynx and peeping under the edges of the velum; evidently the posterior nares were involved, and probably the whole of the nasal cavity, as evidences of the membrane cotld be seen in the nostrils. I now ordered 
ten drops of a solution of biniodide of mercury to next examined, and in her nostril I found a well debe given every ten minutes, and powdered papayotin veloped membrane, although she never had shown to be blown into the throat three times a day, and the slightest sign of sickness.

the spray of peroxide of hydrogen to be used every hour. It seemed, however, as if the reserve forces of the disease in the inaccessible portions of the posterior nares were to be victorious, for as fast as the membrane was removed by the remedies employed, it was reproduced, even encroaching a little upon the unaffected tissue in the interval between the applications; indeed it did descend to the larynx, and impending suffocation kept me for some days in constant expectation of having to perform tracheotomy, which the parents desired should be done if necessary. Fortunately, however, the progress of the disease was arrested, and the use of the remedies gradually discontinued, beginning with the papayotin, followed by the peroxide of hydrogen, the frequency of the doses of the biniodide of mercury being lessened, until three doses daily only were given, and this was continued until January 9, when it also was discontinued. The patient made a perfect recovery without any symptoms of unpleasant sequelæ.

In this case, the solution of biniodide was not sprayed into the nose, as it is now my custom whenever there is reason to suspect infection in the nares. When this is done, the solution of biniodide and the peroxide are used alternately, allowing a sufficient interval of time to elapse, so that the one solution will not decompose the other, as might be the case if they were used immediately after each other. In no case have I considered it necessary to blow the papayotin into the nostrils, because there is not here the danger of suffocation constantly before our eyes.

Case 5.-I was called to see R. F., aged about twelve years. Her symptoms were of some low type of fever, temp. ror, pulse 9o, skin dry, face of a pale, dusky hue, eyes slightly suffused, no headache or other pain, bowels regular, urine normal, slight thirst, no appetite, tongue moist; there had been slight epistaxes but no abdominal symptoms, no glandular swellings. These conditions continued without any important variation for nearly three weeks, when a patch of diphtheritic membrane appeared in the throat, and shortly after I noticed it in the nostril, and now for the first time could any swelling of the cervical glands be detected. Treatment with sol. binioclide of mercury, and with the peroxide of hydrogen was now begun, using other remedies alternately by the atomizer to the nostril and to the pharynx, and cleansing out the throat twice daily with a brush. Within a week, all trace of membrane had disappeared, and the family having moved to another house, the child made a rapid $r$ covery.

A few days afterwards, being called to the patient mentioned above, my attention was directed to a younger sister who was looking badly, but did not complain of being sick. Beyond her paleness and loss of appetite, and a little bleeding at the nose, which had recurred for several days, I could find nothing, until upon a very careful examination of the nostril I noticed a slight deposit, which of course stamped the case.

The same treatment was pursued in these three cases; they all progressed favorably without noteworthy incident, and made good recoveries without any sequels. The occurrence of these cases, including all the children of the household, naturally led to an investigation of the causes, which lay behind this invasion of disease. Upon inquiry, I found that the mother and also the nurse of the children had been out of sorts for some time; the mother particularly complaining of sore throat, but without deposit; the father of the children, was in good health, but his occupation kept him much out of doors. The floor upon which the family slejt was divided into three rooms, one of which was a bath-room containing a water closet. The door of the bath-room was within about a foot of the door of the room in which the children slept. These two rooms occupied the southern side of the building. I found that the doors and windows of all the rooms, including the bath-room, were habitually left open, so that the air from the bath-room had every opportunity to circulate through the sleeping apartments. This house was the centre tenement of a block of three houses, all newly built and recently occupied; yet in the house on one side of that in which my parents resided, there had been one or more cases of typhoid fever, and the inhabitants of the house on the other side were constantly ailing with malarial fever, they said. An inspection of one of the houses was made by a sanitary engineer, showing many defective points in the plumbing, one house being a type of the others.

The remaining cases developed no new features, and it is therefore unnecessary to burden this paper with an itemized report of them; they were all treated upon the principle already set forth, and in none of them was there any unpleasant result. I am confident, moreover, that several other cases of diphtheria have been successfully treated upon this plan, by the relatives of patients without calling in medical aid. The prescriptions were renewed, and the treatment carried out, as I had directed for other members of the same family, or in a friend's family. I am warranted in this belief by the descriptions of the cases given to me later; of course these are not included in the number mentioned here.

There are some cases of diphtheria, in which the membrane is almost the last, or among the last symptom to appear; or it might be safer, perhaps, to say, that the membrane appears very late upon a part open to inspection, if it appears at all. It is of vital importance to be able to diagnosticate such cases of latent diphtheria, and in some cases, I think it can be done with a fair degree of certainty. A strongly marked case of this kind is No. 2, and any case presenting such a train of symptoms, might be well looked upon as so suspicious that the physician would feel himself warranted in adopting an anti-diphtheritic treatment, even though he might hesitate to report such a case to the health authorities.

In discussing this plan of treating diphtheria, I

The remaining child, the youngest of the three, was may be met by the assertion, that the use of mercurial 
salts as remedies in this disease, is old and well known; but be it observed, that I claim for the biniodide of mercury a greater power than is possessed by any other mercurial preparation, more especially when held in solution by iodide of potassium. It is a very common error to mentally group a series of preparations of one base as being one and the same in a therapeutic point of view; than this there can be nothing more erroneous, nothing more likely to lead to fallacious conclusions or to develop unexpected, if not disastrous results. Simply to say that a case of diphtheria was treated with mercury, is to say nothing. The preparation must be known, and as the mode of administration changes the therapeutic action of the remedy, this also should be stated. Even when most accurately described and most carefully followed, it seems often impossible to attain the re. sults claimed for a remedy. Certain individuals seem to acquire a dexterity in the use of a medicine altogether unattainable by others. Thus some seem to succeed admirably with benzoate of soda in the treatment of diphtheria, others with chlorate of potash and muriated tincture of iron, others with salicylic acid, some with resorcin, some with pepsin and dilute sulphuric acid, etc. Let it be understood then, that I do not propose this as a specific treatment for diphtheria, warranted to succeed in every case, by whomsoever employed; but, I bring it before the Association as a method worthy of trial, at least, and as likely to prove useful in the hands of many practitioners.

Judging from the reports made to the Academy of Sciences, by M. Marcand, (Lancet; Scientific American, January 24, I885), other vegetable juices may be found, which will act more powerfully upon the diphtheric deposit than papayotin, instance the agave. The author ascribes the action of these juices to a micro-organism, and as in the microscopic world, its members find their sustenance by the destruction of each other, so, in the depths of microscopic life the organisms subsist the one upon the other, and hence it is well within the range of probability that some microbe may yet be discovered, which will attack and destroy the bacterium of diphtheria; or it may be that other local applications will be brought forward, having a more powerful action upon the deposit, as for example iodoform, which I have seen acting well.

After a careful consideration of the subject, I think it may safely be asserted that no treatment of diphtheria is to be relied upon which neglects the possibility of blood-poisoning, and fails to provide a remedy for it. To summarize then the present treatment, it includes: I, A blood antiseptic, which is also; 2, a local germicide; 3 , a softening agent or digestor of the membrane; 4 , a solvent of the membrane. Let us hope that the future will give one remedy combining these essential characteristics.

These suggestions, it is hoped, may be of some value in view of the possible, nay probable, bacterial origin of diphtheria (see New' York Medical Journal, January Io, I 885, p. 49). In the matter of precautions to be taken to prevent the spread of diphtheria, the pamphlet issued by the Michigan State Board of Health, (Gaillard's Medical Journal, February, i 885, p. $197 \mathrm{I}$,) might be consulted with advantage.
Dr. SEARs, of Texas, while having no experience with the bin-iodide of mercury, had given the bichloride a fair trial, but could not recommend its tuse; indeed his success, no matter what drugs were used, was decidedly poor, as fully one-half of all his cases had proved fatal.

DR. WALKER, of Arkansas, remarked that in the city of I.ittle Rock, Ark., the bin-iodide of mercury (the drug so highly lauded by Dr. Nunn) had been extensively used during an epidemic with the result that the profession there, numbering some forty regular physicians, had declared it worthless as a curative agent in diphtheria. The doctor, in common with many of his brethren, had at one time believed that potass. chlorate and tr. ferr. mur. freely used could be relied on to cure diphtheria, but a fuller experience with the disease had convinced him that it was futile to look for anything like specific effects from any course of medication whatever, and he feared that the treatment so highly spoken of by Dr. Nunn would prove no exception to the rule.

Dr. CATIIN, of Wisconsin, had also congratulated himself on his ability to successfully deal with diphtheria; his plan was one or more large doses of quinine as an initiative, followed by tr. iron and potass. chloras in full doses frequently repeated. During one epidemic he had treated 80 cases in this way, and lost only one patient; but, unfortunately, in the next epidemic the treatment wholly failed. He could say nothing more favorable in regard to mercury, having given the bichloride in a sufficient number of cases to show that it produced no particular effect as a remedial agent in these cases. The disease was, to all intents, a blood-poison; patients suffered very much as they would after a snake-bite, and this offered the only correct clue to treatment, namely, alcoholics in anything like severe cases (and in mild cases little was required, beyond prudent hygienic measures) was the sheet anchor and ought to be given for their effect. The tolerance of alcohol in diphtheria was often as marked as in snake-bite. Of course proper nutriment, as milk, must also be administered as necessary.

Dr. Weichselbati, of Savannah, Ga., had treated diphtheria with the iron and potash, and had seen no particularly good effects; indeed he had formerly concluded that it was a disease over which no known remedy had any good effect whatever; latterly, however, he had pursued a course similar to that advocated by Dr. Nunn, and he was bound to admit that the bin-iodide of mercury and the other drugs alluded to by Dr. Nunn in the paper just read exerted a really curative influence on the disease, an influence that so far as he knew was unparalleled in the history of diphtheria.

DR. UPHAM, of Vermont, had been meeting with diphtheria in its various forms since 1860 . His experience was quite extensive, and he had earnestly sought for some remedy in which confidence could be placed, but he confessed himself appalled at the terrible mortality of the disease, and the utter failure of treatment to lesssen that mortality.

DR. Catlin was of opinion that we were yet in the dark, both in regard to the real nature of diph- 
theria and the principles upon which treatment should be conducted, and considered that the vast number who are victims every year of the disease. ought to stimulate intelligent encuiry on the subject of prophylaxis and treatment.

1)R. Holmiday, of La., having observed diphtheria ever since 1854 , thinks it milder now than formerly. In regard to the problem whether diphtheria is a local or a constitutional disease in the beginning, the speaker was still unable to decide definitely; indeed, " there were so many sources of error, that further observation by intelligent and impartial investigators was much needed to settle this vexed, though all important, (question.

As regards the aphonia that is occasionally present in diphtheria, the speaker stated that it might be caused either by stenosis or odema of the vocal cords and their allied structures, but so far as he knew we were unable to differentiate between the two processes. Inr. Holliday further remarked that recovery was rare in cases of complete aphonia occurring in the subjects of diptheria, yet it occasionally happened; in his own practice he had met with such recoveries.

1)R. NunN closed the discussion by remarking that he did not offer a specific for all cases of diphtheria, but as he had obtained results from the treatment outlined in his paper so much surpassing anything else with which he was accuainted, he merely wished the profession to fairly try his plan, and he believed that results the most beneficial could be looked for.

PRIMARY MALIGNANT DISEASE OF THE KIDNEYS.

\section{BY GEORGE MINGES, M.D.,}

OF DURUQUE, IOWA.

(Concluded from page 627.)

Prognosis.-Unless interfered with by nephrectomy, malignant disease of the kidney inevitably ends in death in from four weeks to five or six years. One case has been known to last i 8 years, but the average duration given by Roberts is $21 / 2$ years, being almost three times longer in adults than in children. By adding to Roberts' cases those of my table occurring since 1866 , we find the average duration in 28 adults to be about $2 \frac{1}{2}$ years; in 36 children about 9 months. Of course these figures can only be ap)proximative, and are probably below the reality, as the disease may remain latent for a time; yet the proportion is probably about correct.

Temporary improvement has occurred in several cases, but sometimes this was due to the removal of complications. The fatal termination is generally bronght about by a gradual wearing out of the vital powers, although sometimes death occurs rather unexpectedly.1 It may also be hastened by rupture into the peritoneal cavity or perforation of the parietal walls. The occurrence of profuse hæmaturia, as a rule, does not hasten the termination, although in Döderlein's case death is said to have occurred from hemorrhage into the tumor, and in one of my cases

1Cases 6,31 and 57 of table. almost continuous vesical tenesmus came near causing death." Uriemia has been the determining cause of death in a few cases, ${ }^{2}$ and in one case stercoraceous vomiting." 'The inferior vena cava being filled with clots in such a great proportion of cases, I am surprised not to find any deaths from embolic processes.

According to Roberts, cancer of the kidney proves fatal less quickly than cancer of other internal organs, probably becanse there is another kidney to perform the functions of the diseased one, and because, from its situation, it has sufficient room to develop, for some time without interfering with the functions of other vital organs.

Treatment.-In the majority of cases of cancer of the kidney, the treatment will have to be symptomatic, as the diagnosis is generally made comparatively late. The pain, which is present in a certain proportion of cases, must be subdued by anodynes, gastric symptoms met according to the individual indications, and by tonic treatment and nourishing diet the fatal termination may perhaps be postponed for a short time. As it at present seems a fashion to give arsenic for all varieties of malignant disease, it is perhaps well to administer it in these affections, although it is doubtful whether any benefit is derived from it. The himaturia, when profuse, demands attention, and sometimes severely taxes the skill and patience of the physician. Absolute rest in bed is to be enjoined, anodynes administered to allay anxiety and irritation, and stimulants and drugs which irritate the kidneys avoided, although small doses of turpentine may have a hremostatic influence. Cold may be applied externally, and ergot, acetate of lead, gallic acid, and other astringents given internally. Generally the hæmorrhage finally ceases, probably spontaneously, perhaps never to return, or, it may be, to come again in frequent attacks. Vesical tenesmus, due to the passage of clots, is to be relieved by anodynes and, if necessary, by washing out the coagula through a catheter, with tejid water or mild alkaline and antiseptic solutions. I will now present the report of the following unique case, a partial report of which I have already made to the Inubuque Medical Society, in February, I880, under the title of "A Case of Paroxysmal Hamaturia; Operation of Cystotomy to Remove Clots; Improvement."

Case V.-Dr. H. J. R., of Dubuque, Swiss, æet. 69 years, came under my treatment in November, I879, for hamaturia, which had troubled him at intervals for several years. During childhood he had enuresis nocturna, and since that time he has been forced to arise three or four times every night to urinate. The attacks of hicmaturia came on without premonition in the midst of apparent good health, generally after drinking beer, and lasted from a few hours to several days; generally causing no symptoms aside from a sudden and imperative desire to urinate, and not hindering him in the fulfillment of his professional duties. As a rule, the hamorrhage was slight, the blood being intimately mixed with the urine. Four years ago, retention was several times caused by large coagula, necessitating the use of the catheter, and once he was piched up in the streets insensible, remaining in that condition until morning. For a while patient discontinued the use of alcoholic beverages and soda-water, as they seemed to stand in a causative relation to the attacks. On January I4, I880, having had no hamorrhage for several weeks,

'Case 57 of table.

2Cases 7 and 12 of table.

Ciase 34 of table. 